Nevertheless, in the case of engineering education, Arabization policies produce professionals handicapped by the scarcity of translated books. Further, engineers experience great difficulty in remaining professionally up-to-date. As a result, the Arabization of the sciences, while promoting an agenda of "decolonization," paradoxically reinforces Syria's dependence on the former colonial countries in terms of the engineering sciences and technological knowhow. This problem may go unsolved given the limited financial resources of scientific institutions in Syria and in the Arab world in general.

Arabization policies are not specific to Syria. Yet, the paradigm behind the politics of Arabization in such countries as Syria and Algeria is the substitution of foreign languages (French, English) with Arabic. By contrast, the Tunisian experience is somewhat different as the state imposes Arabic only on certain parts of the curriculum. At the same time, Tunisian students must be proficient in
French, and sometimes even in English, to remain current with foreign sources and textbooks. Syrian university officials perceive such policies to be rather "schizophrenic" in their effects.

\section{Conclusion}

Finally, I am aware that instructional methods in Syrian universities cannot be separated from other general higher education issues-such as, material and financial capabilities, admissions policies, and the imbalance between the huge number of students in a "mass" public system and the small number of faculty. Furthermore, university and faculty libraries are poorly endowed, and there are always difficulties in obtaining foreign publications. This article has attempted to cover problems not directly related to financial capabilities but rather to the underlying educational philosophy in Syrian higher education.

\title{
Crossing the Distance: The Open University in the Arab States
}

\section{André Elias Mazawi}

André Elias Mazawi is senior lecturer in sociology of education, School of Education, Tel-Aviv University. Address: School of Education, Tel-Aviv University, P.O. Box 39040, Tel-Aviv 69978, Israel. E-mail: <mazawi@post.tau.ac.il>.

$\mathrm{T}$ he concept of an open university and, by implication, that of distance learning remains a widely discussed issue across the Arab states, although open universities are still limited to a very small number of institutions or programs. Institutional, economic, logistic, and political issues are at stake-factors that impede the dissemination of distance higher education in the Arab states. Questions pertaining to inter-Arab relations have also affected the feasibility of such a project. Several attempts to establish open universities have been made since the 1980s. One of these were discussions for the establishment of an Open University for the Gulf States. Other initiatives were undertaken by the Arab League Educational, Cultural and Scientific Organization, as well as by Spain and Morocco in the mid-1980s. More recently, a proposal to establish an Arab Satellite University of Science and Technology was submitted to UNESCO by the U.S.-based National Technological University.

The first full-scale open university to operate remains Al-Quds Open University (QOU), a Palestinian institution opened in Jerusalem in the latter half of 1991. Contacts for its establishment were undertaken between UNESCO and the PLO as early as the mid-1970s, and its first television and radio programs were launched in the mid-1980s. QOU's offices in Amman function as a liaison office coordinating educational matters with the Jerusalem headquarters. The institution extends its services to seven "educational regions"-namely, Jerusalem, Nablus, Ramallah, Bethlehem, Hebron, Gaza, and Jericho. It also operates two study centers, in Tulkarm and Jenin. Based on a credit-hour system, the university grants the equivalent of a B.A. and B.Sc. in a wide array of specializations in the humanities, social sciences, sciences, and educational technology. Quite recently, QOU obtained recognition from the Association of Arab Universities (AArU), becoming the first such higher education institution to join the association.

Calls in favor of establishing an open university for the Arab states continue to be made. It is widely held that an Arab open university would foster cooperation in the field of higher education as countries in the region work to develop their higher educational systems in response to current challenges. Such an institution would also, it is said, provide access to higher education in the region without discrimination based on nationality or gender. Arab officials appear to echo such calls when they stress the need for new alternatives for bringing about the reform and diversification of higher education.

\section{Marginalized Groups}

Women across the Arab states are the largest group directly affected by the dissemination of distance education opportunities-particularly in the Arabian Peninsula and the Magbrib. In Saudi Arabia, for instance, an open university was pointed to as a way to accommodate increased access for women and respect for Islamic customs regarding 
segregation of the sexes and woman's traditional role as wife and mother. It was further indicated that external study, or intisab, a method that enables women to pursue higher education without attending lectures, has not successfully met the increasing demand for higher education opportunities. Recent reports announced the imminent opening of QOU branches in the United Arab Emirates, which would offer courses "to those who work or have family commitments" by providing higher education to students "where they reside."

\section{Women across the Arab states are the largest group directly affected by the dissemination of distance education opportunities}

The open university has become a viable opportunity for Palestinians, too. QOU has enabled several thousand Palestinians in the West Bank and Gaza Strip (and, to a lesser extent, within Israel), who do not otherwise have access to higher education, to undertake higher education studies and thus qualify for a wider spectrum of occupational opportunities. Moreover, some Palestinian and Arab security prisoners held in Israeli prisons, especially those sentenced for longer periods of confinement, see open university studies as a viable opportunity. Attempts by QOU to introduce its curricula to this group have reportedly met with difficulties. Some inmates have consequently enrolled in the Israeli Open University, where studies and materials are in Hebrew.

Increasingly, open university programs from outside the Arab states are also directing themselves toward other locally marginalized groups. For instance, in 1997, India's Indira Gandhi National Open University began offering courses abroad for the first time-in Bahrain, Kuwait, Oman, Qatar, and the UAE-in response the growing demand for higher education opportunities, particularly among Indian expatriate workers in the Gulf states.

\section{Crossing the Distance}

Efforts to extend alternative higher education opportunities to marginalized groups and isolated communities in the Arab states remain quite modest. The dual approach to distance education, whereby a university offers outreach courses in addition to its regular curriculum, has yet to be instituted.

Some have argued that for open university programs of study to succeed, as legitimate venues of mobility they should be launched through regionalized schemes, rather than through a centralized (pan-Arab) institution. Nevertheless, expanding open university programs would most probably speed up the process of knowledge commodification, which is already under way as part of the privatization of higher education in several Arab states (e.g., through the opening of foreign-university affiliates). As knowledge becomes increasingly transferable across distances, its commodification for marketization purposes will be affected by competition.

\section{Key Public Policy Issues in the United States}

\section{Arthur M. Hauptman}

Arthur M. Hauptman is an independent consultant specializing in higher education finance and public policy issues. Address: $2701 \mathrm{~N}$. Upshur Street, Arlington, VA 22207 USA. E-mail: <hauptman@erols.com>.

Since 1994, the Association of Governing Boards, an $\checkmark$ American organization representing boards of trustees of colleges and universities, has published a series of volumes that identify the leading public policy issues affecting higher education in the United States. The 1999-2000 edition in this series was recently published and, as the following list indicates, the top 10 issues in the current biennium have much relevance to trends and conditions in international higher education.

\section{Teacher Preparation}

Teacher supply and quality issues are at the top of the education agenda in the United States as in many other coun- tries. In the United States, the issue of teacher supply is linked to the daunting demographics as growing numbers of children outstrip the ability of local school districts to educate them. The teacher shortage is exacerbated by doubts about the ability of higher education institutions to produce qualified teachers. One expressions of these concerns is recent federal legislation requiring universities to publish the pass rates on state teacher competency tests for their recent graduates.

\section{Affordability vs. Access}

Although the United States continues to have the highest participation rates in higher education in the world, the gap between rates for rich and poor students has not narrowed over time. Amid rising concerns about whether the most economically disadvantaged students will be able to afford postsecondary education, many states and the fed- 